\title{
Rural Space Classification and Value Evaluation Under the Perspective of Rural Revitalization Strategy
}

\author{
Lu Sun ${ }^{1, *}$, Binglei Xie ${ }^{2}$, Hongwei Ge ${ }^{3}$ \\ ${ }^{1}$ Harbin Institute of Technology, Shenzhen Comprehensive Traffic Design and Research Institute Co. \\ ${ }^{2}$ Harbin Institute of Technology \\ ${ }^{3}$ Shenzhen Comprehensive Traffic Design and Research Institute Co. \\ *Lu Sun.Email:SUN_luzy@126.com
}

\begin{abstract}
Based on the judgment of the current major social contradictions, the stage of urbanization development and the law of development of urban-rural relationship, China proposed the rural revitalization strategy in the face of the reality of rural development. As an important carrier of economic, social, cultural and ecological factors, rural space needs to be studied in the context of this strategy, so as to provide a scientific basis for subsequent village planning and directional guidance for village development. With this objective, this study defines the spatial connotation of "Production-LivingEcology" space in rural areas based on the current land use classification, then correlate the type of space with the "Production-Life-Ecology" function. The selection of spatial function evaluation indexes is based on the value of ecosystem functions, and the direct measurement method of biophysical processes in the direct assessment method is used, and the indirect assessment method of value volume conversion method is used to assist in the comparison and combination of measurement. Finally, Wuhan rural area is selected as the empirical object to verify the idea of spatial function value evaluation, and GIS spatial technology is used to express the presentation and visualize the spatial characteristics of Wuhan rural area.
\end{abstract}

Keywords: Rural Revitalization, "Production-Life-Ecology" space, Space function, Value Evaluation

\section{INTRODUCTION}

The rapid progress of industrialization and urbanization in China has triggered dramatic changes and profound transformations in the economy, society, environment and culture of the countryside[1], such as rural hollowing, farmland abandon, public service shortage and rural landscape alienation etc. Since the 21 st century, China has put forward a series of policies to support urban-rural integration, new rural construction, urban-rural development integration, and new urbanization in response to the rural development dilemma. Since 2004, the "No. 1 Document" issued by the Central Committee of the Communist Party of China for 15 consecutive years has focused on the " issues concerning agriculture, countryside and farmers" and provided a number of policies and construction funds for rural economic development, habitat improvement, and basic public service enhancement. However, the influence of the long-term urban-rural dichotomy, the preference for urban priority development, and the inherent weakness of rural development still exist objectively. Based on the analysis and judgment of the main contradictions of Chinese society, the stage of urbanization and the law of development of urban-rural relationship, the Communist Party of China (CPC), taking into account the current situation, clearly proposed the strategy of rural revitalization at the 19th National Congress, indicating that it would focus on solving the outstanding problems of unbalanced urban-rural development and inadequate rural development, and promoting the modernization of agriculture and rural areas in accordance with the general requirements of "prosperous industry, ecological livability, civilized countryside, effective governance and prosperous life"[2]. The countryside, compared to the town, is a complex system composed of economic, social and environmental elements, with agriculture as the main economic activity and a relatively dispersed population, and the countryside space is the specific spatial bearing of this complex element. Scientific and reasonable planning and utilization of rural space is an important prerequisite and foundation for the implementation of rural revitalization strategy. Therefore, it is necessary to 
establish a set of spatial function evaluation system applicable to rural regions from multiple perspectives such as regional, economic, ecological, social and cultural perspectives, make objective evaluation of rural space and classify rural types, provide ideas for the optimization and integrated development of rural space, so as to use planning means for reasonable intervention and promote the orderly and gradual evolution of rural space in the context of rural revitalization strategy.

\section{CONNOTATION AND DEFINITION}

The "Production-Living-Ecology" space is the collective name of production space, living space and ecological space; production space refers to the space with the characteristics of output products, related to the industrial structure; living space refers to the space of human daily behavioral activities, related to carrying activities and housing security; ecological space refers to the specific geographical space that provides ecological products and services, related to the natural local, with ecological protection function. Robert Gilman[3], Kates[4] and others have pointed out that ecological space is the basis of production space and living space, and supports these two spaces to achieve the established functions, which is the key to harmonize the relationship between human and land and realize the sustainable development of the region. Specifically, the specific connotation of the " Production-Living-Ecology " spaces in villages is as follows:

Production space: It is a rural field in which various production subjects carry out various production activities and establish economic relations with each other, which may produce a variety of result representations under the interaction with production space, with certain structural forms and functional combination mechanisms, and belongs to a manifestation of the territorial system of human-land relations.

Living space: The spatial boundary is formed by the daily life range of local villagers in the countryside, and the way of life forms the spatial structure, which is both regional space and social space. The main body of using rural living space is the villagers, and the villagers' daily behavioral activities are both the use and reproduction of the living space[5].

Ecological space: According to China's ecological space control policies and land use types, ecological space can be subdivided into geographic space with important ecological protection and geographic space with important ecological services, the former type of ecological space has the function of preventing and mitigating the occurrence of natural disasters, such as wind and sand control, flood storage, geological disaster protection, etc.; the latter type of ecological space can provide ecological services and ecological The latter ecological space can provide ecological services and products, such as water connotation, groundwater recharge, biodiversity maintenance, etc. Specifically, at the rural geographical level, nature reserves, scenic spots, water conservation areas, forest parks, natural waters, agricultural and forestry land for non-agricultural production and other non-construction land should be classified within the ecological space.

\section{RESEARCH IDEA}

\subsection{Rural "Production-Living-Ecology" space land classification}

First of all, the construction of the rural spatial value evaluation system needs to be based on the current function of the land and the specific definition of the " Production-Living-Ecology" spatial functions, according to the above analysis of the connotation of the rural " Production-Living-Ecology " space, this study defines the specific functions of the rural " Production-LivingEcology " space as follows.

(1) Production function: refers to the land as the object of labor, directly or indirectly based on material production and provision of products and services.

(2) Living function: refers to the various spatial bearing functions provided by the land in the process of human life, which can be divided into life bearing, material security and spiritual security according to the type of activities and needs.

(3) Ecological function: In order to maintain the survival and development of human beings, the ecosystem provides the natural basis and guarantee functions in the process of its ecological role, mainly divided into two kinds of accommodating and regulating functions.

Then, based on the current Chinese standard of Current Land Use Classification (GB/T 21010-2017) and the specific connotation of the " Production-LivingEcology " spaces in rural areas, the dominant functions of various types of rural land uses are determined and the land uses are classified according to their dominant functions.

Finally, the functional definition of rural "ProductionLiving-Ecology" space and the current land use classification of rural areas are correlated, i.e., the matching of land use function and land use type, forming the land use classification system of rural "ProductionLiving-Ecology" space for this value evaluation.

\subsection{Evaluation of the spatial function of the "Production-Living-Ecology" of the countryside}

The value evaluation of spatial functions is essentially the value expression of spatial functions under a unified 
standard. The common calculation methods of value quantity are mainly divided into two kinds of methods: direct evaluation method is the method of quantitative calculation of each index in the ecosystem directly by using market theory methods, such as market value method, alternative cost method and conditional value method, etc. This method is relatively more accurate but has high dependence on the accuracy and magnitude of data; indirect evaluation method refers to the method of quantitative calculation of each index in the ecosystem based on the theory of market economics, after This method is relatively weak in terms of accuracy and spatial heterogeneity but is highly adaptable and operable.

Therefore, in this study, the direct measurement of biophysical processes in the direct valuation method and the indirect valuation method of the value-volume conversion method were combined to evaluate each function of the space with a uniform standard monetary value through the intermediate and final material conversion of ecosystem service value equivalents. In this study, the ecosystem service value equivalents (ESVs) were selected from the Chinese ecosystem service equivalents per unit area proposed by Xie Gaodi and other scholars[6] and revised in 2015 (as shown in Table 4), which are highly recognized at home and abroad, used in many studies, and applicable to the Chinese context. The spatial evaluation system of "Production-Living-Ecology" space in rural areas of Wuhan City was selected as the object of empirical research, and the results were finally presented and expressed through GIS spatial technology, and the overall research idea is shown in Figure 1.

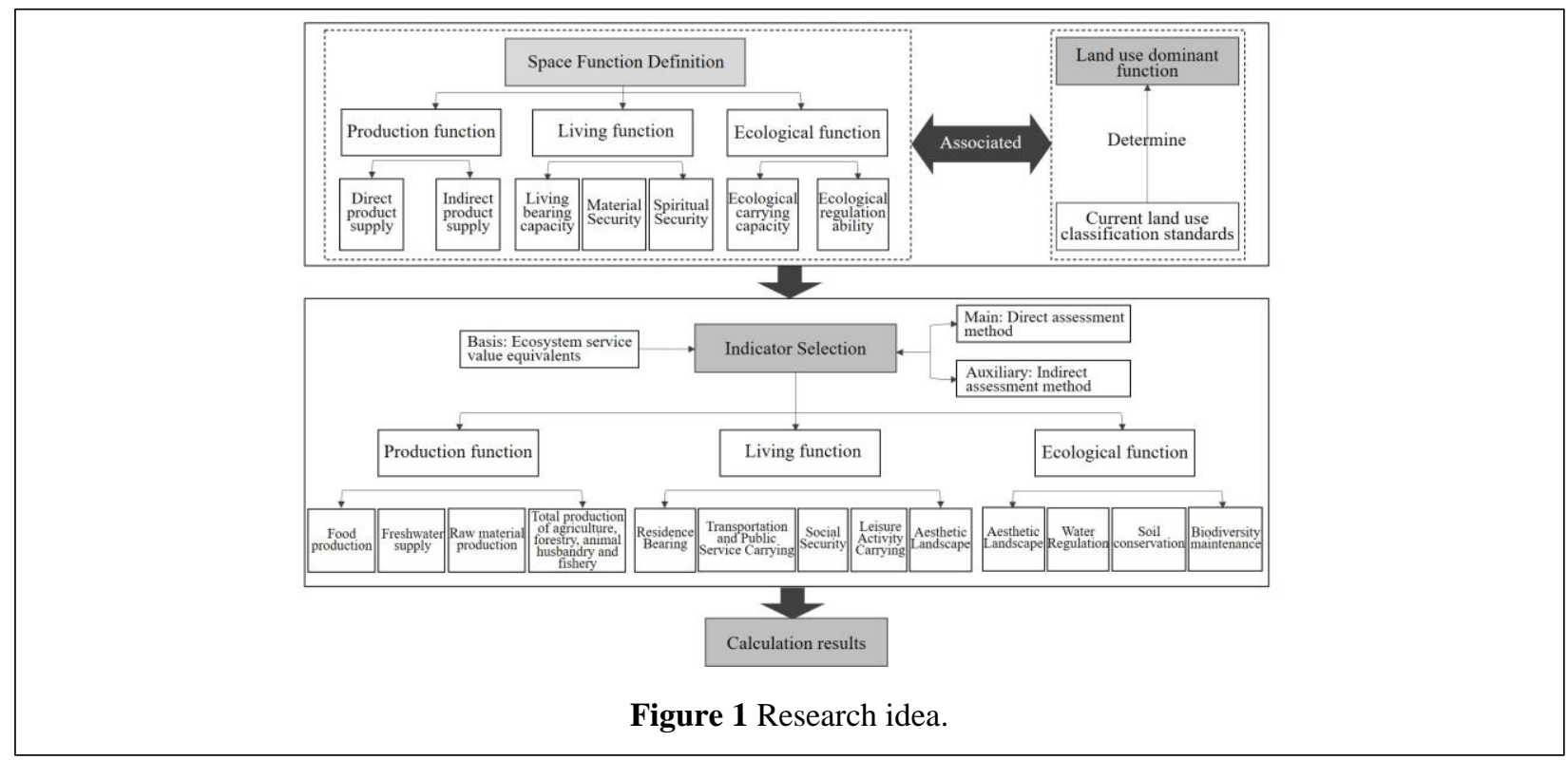

\subsection{Indicator Selection}

Based on the classification of 16 ecosystem functions proposed by Costanza and other scholars[7], Combined with the above definition of the "Production-LivingEcology" spatial functions, land use classification and the reality of rural space in Wuhan City, conducting metrics screening the screening. 
Table 1 Ecological service value equivalent per unit area of Chinese ecosystems

\begin{tabular}{|c|c|c|c|c|c|c|c|}
\hline Level 1 Type & Level 2 Type & Forest & Grassland & Farmland & Wetlands & $\begin{array}{c}\text { Rivers / } \\
\text { Lakes }\end{array}$ & Desert \\
\hline \multirow{5}{*}{ Supply Services } & Food production & 0.33 & 0.43 & 1.00 & 0.36 & 0.53 & 0.02 \\
\cline { 2 - 8 } & $\begin{array}{c}\text { Raw material } \\
\text { production }\end{array}$ & 2.98 & 0.36 & 0.39 & 0.24 & 0.35 & 0.04 \\
\cline { 2 - 8 } & $\begin{array}{c}\text { Climate } \\
\text { regulation }\end{array}$ & 4.07 & 1.56 & 0.97 & 13.55 & 2.06 & 0.13 \\
\cline { 2 - 8 } & $\begin{array}{c}\text { Hydrological } \\
\text { regulation }\end{array}$ & 4.09 & 1.52 & 0.77 & 13.44 & 18.77 & 0.07 \\
\cline { 2 - 8 } & $\begin{array}{c}\text { Waste disposal } \\
\text { Support Services }\end{array}$ & 1.72 & 1.32 & 1.39 & 14.40 & 14.85 & 0.26 \\
\cline { 2 - 8 } & $\begin{array}{c}\text { Soil conservation } \\
\text { Biodiversity } \\
\text { maintenance }\end{array}$ & 4.02 & 2.24 & 1.47 & 1.99 & 0.41 & 0.17 \\
\hline \multirow{2}{*}{ Cultural Services } & $\begin{array}{c}\text { Aesthetic } \\
\text { Landscape offers }\end{array}$ & 2.08 & 0.87 & 0.17 & 4.69 & 4.44 & 0.24 \\
\hline
\end{tabular}

\subsubsection{Evaluation index of production space function}

According to the definition of the spatial function of rural production in the previous section, the production function refers to the function of using the land as the object of labor and directly or indirectly using it as the basis for material production and provision of products and services. Focusing on the selection of indicators from the material supply aspect, four indicators of food production, fresh water supply function, raw material production and total output value of agriculture, forestry, animal husbandry and fishery are selected to evaluate the value of rural production space function.

\subsubsection{Evaluation index of living space function}

According to the definition of rural living space function in the previous section, the living function refers to the functions carried by the space in the process of human activities. Focusing on the material security aspect for index screening, a total of five indicators are selected to evaluate the value of rural living space function, such as residence carrying, transportation and public service carrying, social security, leisure activity carrying and aesthetic landscape.

\subsubsection{Evaluation index of ecological spatial function}

According to the definition of ecological space function of the countryside, it refers to the natural foundation and guarantee function provided by the ecosystem in the process of ecological action to maintain human survival and development. The indicators are selected from the ecological regulation aspect, and a total of five indicators are selected to evaluate the ecological space function value, including climate regulation, water regulation, waste treatment, soil conservation and biodiversity maintenance.

\section{CALCULATION METHOD}

\subsection{Data source}

The data of this study are mainly divided into three categories: urban and rural land use, regional ecological environment, and socio-economic development. The urban and rural land use data are based on the Wuhan administrative division map, the current land use map, the landsat 8 remote sensing satellite map and other vector maps (2016) and other auxiliary maps and related plans; the regional ecological environment data are obtained from the National Ecosystem Observation and Research Network, the China Biodiversity and Economic Value Assessment of Ecosystem Services website; socioeconomic development data from Wuhan City 2017 Statistical Yearbook, Hubei Province 2017 Rural Statistical Yearbook, Wuhan Bureau of Land Resources and Planning benchmark land prices and other data, Wuhan City Comprehensive Statistical Annual Report on Land Resources and Planning, Wuhan City New Benchmark Land Price Amendment System, etc. and field survey information.

\subsection{Production space function measurement}

The spatial functions of production are divided into four indicators: food production, freshwater supply function, raw material production and total output value of agriculture, forestry, animal husbandry and fishery for value measurement. Among them, food production and raw material production are calculated by the valuevolume transformation method based on the ecological 
service value equivalent per unit area of Chinese ecosystems in Table 1, freshwater supply is calculated by the direct measurement method of biophysical processes, and the total output value of agriculture, forestry, animal husbandry and fishery is calculated by querying the rural statistical yearbook. Since the value-transformation method is relatively simple to calculate, the calculation of freshwater functional supply indicators [8] is detailed below.

$$
\begin{gathered}
\text { Formula } 1 V_{i, w}=Y_{x j} \times W P ; \\
\qquad \begin{array}{c}
\frac{A E T_{x j}}{P_{X}}=\frac{1+w R_{x j}}{1+w R_{x j}+\frac{1}{R_{x j}}} ; R_{x j}=\frac{K_{x j} \times E T_{0}}{P_{X}} \\
w_{x}=Z \frac{A W C_{x}}{P_{x}}
\end{array}
\end{gathered}
$$

Note: $V_{i, w}$ refers to water production; $W P$ refers to water price per unit area; $Y_{x j}$ refers to annual water production of $\mathrm{x}$ land cover type $\mathrm{j} ; A E T_{x j}$ refers to annual evapotranspiration of $\mathrm{x}$ land cover type $\mathrm{j} ; P_{X}$ refers to average annual precipitation; $\mathrm{w}$ refers to the ratio of annual available water to expected precipitation of modified vegetation; $R_{x j}$ is the actual evapotranspiration to precipitation ratio of $\mathrm{x}$ land cover type $\mathrm{j}$, which is dimensionless data. $K_{x j}$ refers to the vegetation evapotranspiration coefficient; $E T_{0}$ refers to the reference crop evapotranspiration; $\mathrm{Z}$ is the Zhang coefficient, and the value of 3.33 is taken here according to the general situation; $A W C_{x}$ refers to the effective soil water content.

\subsection{Living space function measurement}

The living space function is divided into five indicators for value measurement: residential carrying function, transportation and public service carrying function, social security function, leisure function, and aesthetic landscape function. Among them, the aesthetic landscape function adopts the value quantity transformation method, based on the value equivalent of ecological services per unit area of Chinese ecosystem in Table 4-23; the residential carrying function, transportation and public service carrying function, social security function, and leisure function are calculated by the direct measurement method of biophysical process, and the following are the detailed calculation methods.

\subsubsection{Residential bearing function}

Country residential land:

Formula $2 V_{i, \text { land }}=\left(\right.$ Cost $\left._{i}+R_{i}\right) \times S \times K$

Note: $V_{i, l a n d}$ refers to the price of the land to be valued; Cost $_{i}$ is the cost price of land (in areas where the cost cannot be accounted for, the local compensation standard for land acquisition (per year) is used as a substitute); $R_{i}$ refers to the gain in land appreciation; $\mathrm{S}$ refers to the individual correction coefficient; $\mathrm{K}$ refers to the correction coefficient of the year.

\subsubsection{Traffic and public service bearing function}

$$
\text { Formula } 3 \quad V_{i, \text { land }}=P_{i} \times S \times D
$$

Note: $V_{i, \text { land }}$ refers to the price of the land to be valued; $P_{i}$ refers to the average price of the surrounding land in the area where the land to be valued is located; $S$ refers to the individual correction factor; $\mathrm{K}$ refers to the year correction factor

\subsubsection{Social security function}

The value of social security function includes the value of basic livelihood security function (including pension function) and the value of employment security function, especially in rural areas, arable land and other arable land carries many social security functions such as basic family security, employment and unemployment security, pension security, and medical security supplement.

$$
\begin{aligned}
& \text { Formula } 4 \quad \begin{array}{l}
V_{p}=V_{1}+V_{2} \\
V_{1}=P_{i}+\frac{L}{K} \\
V_{1}=\left(P_{0}-P_{1}\right) \times \frac{B}{K}
\end{array}
\end{aligned}
$$

Note: $V_{p}$ refers to the value of social security function; $V_{1}$ refers to the value of basic livelihood security function; $V_{2}$ refers to the value of employment security function; $P_{i}$ refers to the population carrying capacity of the ith land use mode; L refers to the urban minimum living security level in the study area in the corresponding year; $\mathrm{K}$ refers to the ratio of urban residents' per capita disposable income to farmers' per capita net income in the corresponding year, i.e., urbanagricultural income ratio; $P_{0}$ refers to the population carrying capacity ; $P_{1}$ refers to the minimum carrying capacity of land resources; $B$ refers to the amount of urban unemployment insurance benefits in the study area in the corresponding year.

\subsubsection{Leisure function}

$$
\begin{gathered}
\text { Formula } 5 \quad P_{\text {travel }}=T_{\text {cap }} \times I_{i} \times T_{i}^{-1} \times l / A_{i} \\
\qquad \begin{array}{c}
l=L \times\left(1+a e^{-b t}\right)^{-1} \\
t=E n^{-1}-3
\end{array}
\end{gathered}
$$

Note: $P_{\text {travel }}$ refers to the leisure value of the study area; $T_{\text {cap }}$ refers to the overall tourism environment capacity of the study area; $I_{i}$ refers to the tourism revenue of the study area in year $\mathrm{i} ; T_{i}$ refers to the total number of 
visitors in year $\mathrm{i} ; 1$ refers to the social development stage coefficient; $A_{i}$ refers to the total area of the tourism area; $\mathrm{L}$ refers to the willingness to pay of people in the very rich social stage, taking a value of 1 ; $t$ refers to the time variable, for the social development stage; $a$ and $b$ refer to constants, taking the value of 1 ; e is the natural logarithm; and En refers to the Engel coefficient.

\subsection{Ecological space function measurement}

The value of ecological space functions is divided into six indicators: climate regulation, hydrological regulation, waste treatment, soil conservation, and maintenance of biodiversity, and these five indicators are all measured using the material transformation method, i.e., based on the value of ecological services per unit area of Chinese ecosystems in Table 4 , the value of an ecological space function is equal to the product of the ecological space area occupied by that function and the corresponding value equivalent. The total value of the function is the sum of the value of each function.

\subsection{Evaluation results}

Using the "Production-Living-Ecology" spatial function evaluation method described above, a total of 34 land use types and 14 spatial function indicators were evaluated in Wuhan rural space, and presented through GIS, as shown in Figure 2.

\subsubsection{Production space characteristics}

Figure 2 Spatial distribution of production-living-ecology in rural areas of Wuhan in 2017.

The spatial distribution of production shows obvious "strong functional concentration and decreasing circles" characteristics. In other words, the total value of production functions in the northern region is higher and more scattered, while the total value of production functions in the southern region is lower and more concentrated; with the new town center in the rural area as the core, the production functions are scattered along the main traffic arteries or water systems, in order to the outer circle; the closer to the new town center, main traffic arteries and water systems, the higher the value of production functions, and vice versa, the lower the value.

\subsubsection{Living space characteristics}

The distribution of living space shows obvious characteristics of "township concentration and township dispersion". Since the evaluation of the value of living space function is based on five indicators: residential bearing function, transportation and public service bearing function, social security function, leisure function and aesthetic landscape function, water bodies and mountains are the highest areas in the final distribution of the value of living space function because of their larger area compared with other sites and higher values in the calculation of leisure and aesthetic landscape value. Excluding mountains and water bodies, the distribution of the value of living functions is related to the level of development of town centers, the level of town systems and the scale of agricultural and forestry land in rural areas, and is consistent with the distribution of the value of production functions.

\subsubsection{Ecological space characteristics}

The spatial distribution of ecology is characterized by a significant "concentration of elements in the mountains and water". The distribution of ecological function value is not directly related to the distribution of production and living value, but is directly related to the distribution of natural resources such as water bodies, mountains, woodlands and non-construction land.

\section{CONCLUSIONS}

In the context of rural revitalization strategy, with the transformation of the connotation characteristics of rural spatial governance, rural spatial planning will become a 
platform for the coordination of China's agriculturerelated policies. Through quantitative evaluation of the value of rural spatial functions, it can provide a practical basis for future rural classification and rural dominant development direction, and improve the scientific and operability of rural planning. At the same time, the theoretical methods of rural spatial planning, rural spatial use control and planning permission categories also need to be further explored and studied in depth.

\section{REFERENCES}

[1] ZHOU Lan, ZHAO Qinghong. Reshaping the Beautiful Countryside in the Eyes of Chinese: The Characteristic Pastoral Countryside Construction of Jiangsu Province[J].Urban and Rural Construction , 2020(8):6-13

[2] Central People's Government of the People's Republic of China, Report of the Nineteenth National Congress of the Communist Party of China [EB/OL]. [2021-5-25].

http://www.gov.cn/zhuanti/19thcpc/baogao.htm

[3] PENG Zhenwei . Small Town Development and Implementation of Rural Revitalization Strategy[J]. Urban and Rural Planning, 2018(1):11-16

[4] Robert Gilman, Diane Gilman. Eco-Villages and Sustainable Communities: A Report for Gaia Trust by Context Institute[R].Context Institute. Bainbridge Island,WA, 1991

[5] Halfacree K. Rural space: constructing a three-fold architecture $[\mathrm{M}]$. Cloke P et al. Handbook of Rural Studies. London: Sage,2006: 125-141

[6] Xie Heights, Zhang Caixia, Zhang Reming, et al. Improvement of the valorization method of ecosystem services based on the value equivalent factor per unit area[J]. Journal of Natural Resources, 2015. 30(8):1243-1254

[7] Costanza R, D ' Arge R,de Groot R, etal. The value of the world's ecosystem services and natural capital [J].Nature, 1997.387: 3-15

[8] Tallis H, Polasky S. Mapping and valuing ecosystem services as an approach for conservation and natural- resource management[J].Annals of the New York Academy of Sciences, 2009,1162(1): 265-83 